\title{
Differential Subcellular Targeting of Glutamate Receptor Subtypes during Homeostatic Synaptic Plasticity
}

\author{
Cary Soares, ${ }^{1,2 \star}$ Kevin F. H. Lee, ${ }^{1,2 \star}$ Wissam Nassrallah, ${ }^{2}$ and Jean-Claude Béïque ${ }^{2,3,4}$ \\ ${ }^{1}$ Neuroscience Graduate Program, ${ }^{2}$ Department of Cellular and Molecular Medicine, ${ }^{3}$ Centre for Stroke Recovery, and ${ }^{4}$ Centre for Neural Dynamics, Faculty \\ of Medicine, University of Ottawa, Ottawa, Ontario K1H 8M5, Canada
}

\begin{abstract}
Homeostatic processes are believed to contribute to the stability of neuronal networks that are perpetually influenced by Hebbian forms of synaptic plasticity. Whereas the rules governing the targeting and trafficking of AMPA and NMDA subtypes of glutamate receptors during rapid Hebbian LTP have been extensively studied, those that are operant during homeostatic forms of synaptic strengthening are less well understood. Here, we used biochemical, biophysical, and pharmacological approaches to investigate glutamate receptor regulation during homeostatic synaptic plasticity. We show in rat organotypic hippocampal slices that prolonged network silencing induced a robust surface upregulation of GluA2-lacking AMPARs, not only at synapses, but also at extrasynaptic dendritic and somatic regions of CA1 pyramidal neurons. We also detected a shift in NMDAR subunit composition that, in contrast to the cell-wide surface delivery of GluA2-lacking AMPARs, occurred exclusively at synapses. The subunit composition and subcellular distribution of AMPARs and NMDARs are therefore distinctly regulated during homeostatic synaptic plasticity. Thus, because subunit composition dictates key channel properties, such as agonist affinity, gating kinetics, and calcium permeability, the homeostatic synaptic process transcends the simple modulation of synaptic strength by also regulating the signaling and integrative properties of central synapses.
\end{abstract}

\section{Introduction}

Hebbian forms of synaptic plasticity, i.e., long-term potentiation (LTP) and long-term depression (LTD), exhibit features that are consistent with a synaptic encoding of information and, as such, have come to dominate our understanding of how memories are stored in the brain (Kessels and Malinow, 2009). However, neural network models that implement solely Hebbian plasticity are inherently unstable due to the positive-feedback nature of LTP and LTD (Turrigiano, 2008; Lee et al., 2013). The discovery of homeostatic plasticity has been received with great interest in part because it provides a biologically plausible means to stabilize perpetually active and plastic neural networks (Turrigiano, 2008; Lazar et al., 2009; Lee et al., 2013). Homeostatic synaptic plasticity (HSP) enables neurons to adapt to sustained alterations in overall cellular activity by bidirectionally regulating the strength of excitatory and inhibitory synaptic transmission. For example, neurons respond to prolonged inactivity by a cell-wide enhancement

Received May 3, 2013; revised July 12, 2013; accepted July 16, 2013.

Author contributions: C.S., K.F.H.L., and J.-C.B. designed research; C.S., K.F.H.L., and W.N. performed research; C.S. and K.F.H.L. contributed unpublished reagents/analytic tools; C.S. and K.F.H.L. analyzed data; C.S., K.F.H.L., and J.-C.B. wrote the paper.

This research was funded by the Heart and Stroke Foundation Center for Stroke Recovery, the Canadian Institute of Health Research, the Natural Sciences and Engineering Research Council of Canada, and the Canadian Foundation for Innovation (to J.C.B.). We thank Nina Ahlskog for her valuable contribution in setting up the surface biotinylation assay; Riadh Haj-Dahmen for his assistance in the early phases of the project; and members of the Béique and Bergeron laboratories for helpful discussions.

${ }^{*}$ C.S. and K.F.H.L. contributed equally to this work.

The authors declare no competing financial interests.

Correspondence should be addressed to Jean-Claude Béique, 451 Smyth Road, RGN3501N, 0ttawa, 0N K1H 8M5, Canada.E-mail:jbeique@uottawa.ca.

DOI:10.1523/JNEUROSCI.1873-13.2013

Copyright $\odot 2013$ the authors $\quad 0270-6474 / 13 / 3313547-13 \$ 15.00 / 0$ of excitatory synaptic strength, and adapt to sustained hyperactivity by a global synaptic depression of excitatory synapses (Turrigiano et al., 1998).

Despite enacting fundamentally different roles in neuronal function, Hebbian and homeostatic synaptic plasticity share common synaptic loci of expression. Indeed, both forms of plasticity can manifest through the regulation of postsynaptic glutamate receptor number and/or function. Some, but not all, studies have reported that synaptic strengthening during HSP is mediated by the insertion of GluA2-lacking AMPARs (Ju et al., 2004; Thiagarajan et al., 2005; Sutton et al., 2006; Aoto et al., 2008; Groth et al., 2011), a calcium-permeable subtype of AMPAR expressed at very low levels under baseline conditions in pyramidal neurons (Béique and Huganir, 2009; Lu et al., 2009). Interestingly, this AMPAR subtype has also been implicated in LTP expression (Plant et al., 2006; Guire et al., 2008), although this remains controversial (Adesnik and Nicoll, 2007; Gray et al., 2007). Furthermore, the subunit composition of synaptic NMDARs is also dynamically regulated. Recent work indicates that synaptic NMDAR subunit composition is highly regulated during LTP, with subunit switching occurring as rapidly as synaptic potentiation per se (Bellone and Nicoll, 2007). It remains unclear, however, whether such mechanisms also operate during homeostatic synaptic strengthening.

Here, we show that prolonged network inactivity in organotypic hippocampal slices leads to a cell-wide surface delivery of calcium-permeable GluA2-lacking AMPARs that populate both synaptic and extrasynaptic sites. Synaptic NMDARs, but not their extrasynaptic counterparts, undergo a switch from predominantly GluN2B-containing to GluN2A-containing NMDARs in response to prolonged inactivity. These results, therefore, expand 
the known repertoire of the cellular processes involved in the homeostatic regulation of excitability of CA1 pyramidal neurons. The synaptic homeostatic response is thus not merely limited to the regulation of synaptic strength as a means to control excitability, but encompasses broader alterations that fundamentally influence key features of excitatory synaptic transmission.

\section{Materials and Methods}

Organotypic slice culture. Organotypic slice cultures were prepared using a modified method of the original interface technique (Stoppini et al., 1991). Male and female Sprague Dawley rats (Charles River Laboratories; $6-8 \mathrm{~d}$ old) were anesthetized by isofluorane (Baxter Corporation) inhalation and decapitated according to procedures approved by the University of Ottawa Animal Care Committee. Individual hippocampi were removed in ice-cold cutting solution containing the following (in $\mathrm{mM}$ ): 119 choline chloride, $2.5 \mathrm{KCl}, 4.3 \mathrm{MgSO}_{4}, 1.0 \mathrm{CaCl}_{2}, 1.0 \mathrm{NaH}_{2} \mathrm{PO}_{4}-\mathrm{H}_{2} \mathrm{O}$, $1.3 \mathrm{Na}$-ascorbate, 11 glucose, 1 kynurenic acid, $26.2 \mathrm{NaHCO}_{3}$, saturated with $95 \% \mathrm{O}_{2}$ and $5 \% \mathrm{CO}_{2}$, pH 7.3 (295-310 mOsm/L). Hippocampal slices $(400 \mu \mathrm{m})$ were obtained using an MX-TS Tissue Slicer (Siskyou). Individual hippocampal slices were transferred to membrane inserts (catalog \#PICM03050, Millipore) and maintained in six-well plates at $34^{\circ} \mathrm{C}$ in $95 \% \mathrm{O}_{2}$ and $5 \% \mathrm{CO}_{2}$ containing Neurobasal-A-based culture media. Slice culture media were exchanged at $1 \mathrm{~d}$ in vitro (DIV) and then every 2-3 d thereafter. After 6-8 DIV, tetrodotoxin (TTX; $1 \mu \mathrm{M}$; Tocris Bioscience) was added to the treatment group.

Whole-cell electrophysiology. Whole-cell recordings were performed on CA1 pyramidal neurons from control (CTL) slices or slices incubated for 3-4 d with TTX. For recording, one slice was removed from a culture insert and placed in a recording chamber, and cells in stratum pyramidale of the CA1 subfield were visualized under differential interference contrast using a BX61WI upright microscope [with a $40 \times / 0.8$ numerical aperture (NA) or $60 \times / 1.0$ NA objective; Olympus] or a Zeiss Axio Examiner D1 upright microscope $(40 \times / 0.75$ NA objective). All experiments were performed at room temperature in Ringer's solution containing the following (in mM): $119 \mathrm{NaCl}, 2.5 \mathrm{KCl}, 1.3 \mathrm{MgSO}_{4}, 2.5$ $\mathrm{CaCl}_{2}, 1.0 \mathrm{NaH}_{2} \mathrm{PO}_{4}, 11$ glucose, and $26.2 \mathrm{NaHCO}_{3}$ (or low $\mathrm{Mg}^{2+}$ Ringer's solution containing $0.1 \mathrm{MgSO}_{4}, 3.0 \mathrm{CaCl}_{2}$ ) saturated with $95 \% \mathrm{O}_{2}$ and $5 \% \mathrm{CO}_{2}, \mathrm{pH} 7.3(295-310 \mathrm{mOsm} / \mathrm{L})$. Additional drugs were added to the Ringer's solution, as indicated in the text (in mM): 0.001 TTX, 0.1 picrotoxin, $0.01 \mathrm{NBQX}, 0.05-0.1 \mathrm{DL}-\mathrm{APV}, 0.003$ ifenprodil, and 0.02 1-naphthyl acetyl sperminetrihydrochloride (NASPM; all purchased from Tocris Bioscience). Whole-cell recordings were performed using an Axon Multiclamp 700B amplifier, filtered at $2 \mathrm{kHz}$, sampled at $10 \mathrm{kHz}$, and digitized with an Axon Digidata 1440A digitizer. Borosilicate glass recording electrodes (World Precision Instruments) were pulled using a Narashige PC-10 vertical puller and had resistances ranging from 3 to 5 $\mathrm{M} \Omega$. For voltage-clamp recordings, electrodes were filled with an internal solution containing the following (in $\mathrm{mm}$ ): 115 cesium methanesulfonate, 0.4 EGTA, 5 tetraethylammonium-chloride, $2.8 \mathrm{NaCl}, 20$ HEPES, 3 ATP-Mg, 0.5 GTP, 10 Na-phosphocreatine (all purchased from Life Technologies), and 5 QX-314 (purchased from Abcam), $\mathrm{pH}$ 7.2-7.3 (280-290 mOsm/L). For all voltage-clamp recordings, access resistance was continuously monitored during the experiment by delivering a $5 \mathrm{mV}$ hyperpolarizing step at the onset of every electrophysiological sweep. All recordings were analyzed using Clampfit 10.2 (Molecular Devices) and Origin 8 analysis software (OriginLab). All voltages were left uncompensated. All error bars represent SEM.

For AMPAR current-voltage ( $I-V)$ curves, $0.1 \mathrm{~mm}$ spermine (Tocris Bioscience) was included in the internal solution. To calculate a rectification index for AMPAR $I-V$ relationships, the slope was calculated for both the inward ( -70 to $0 \mathrm{mV})$ and outward $(0$ to $+40 \mathrm{mV})$ portions of the curve, and the ratio of the outward slope over the inward slope was computed (Béique et al., 2011; Granger et al., 2013). The amplitudes of AMPA and NMDA currents for AMPA/NMDA ratios were estimated using the EPSC recorded at $+40 \mathrm{mV}$, based on their respective time courses, as previously described (Béique et al., 2006). For decay analysis of NMDAR-mediated EPSCs [both evoked EPSCs (eEPSCs) at $+40 \mathrm{mV}$ and uncaging EPSCs at $-60 \mathrm{mV}$ ], a biexponential fit was used to calcu- late a weighted $\tau$ value ( $\tau_{\mathrm{w}}$; Vicini et al., 1998). To ensure that all evoked currents were monosynaptic, extreme care has been taken to minimize polysynaptic activity. A glass-patch electrode was used to electrically stimulate glutamate release from axons and was positioned close to the proximal apical dendritic arbor of the recorded neurons. Stimulation intensity was kept low, eliciting eEPSCs of small amplitude $(<100 \mathrm{pA}$, typically $\sim 50 \mathrm{pA}$ ). In some cases, $10-30 \mathrm{~nm}$ TTX was included in the Ringer's solution to dampen polysynaptic activity.

Peak-scaled nonstationary noise analysis of AMPAR-miniature EPSCs. For estimates of mean AMPAR channel conductance $(\gamma)$ and the number of channels exposed to glutamate $(N)$, peak scaled noise analysis of AMPAR-miniature EPSCs (mEPSCs) was performed using Mini Analysis software (Synaptosoft). All recordings with $<50$ events were discarded from the analysis. An average mEPSC waveform from each recording was scaled to the peak of each $\mathrm{mEPSC}$ in the recording, and the variance of current fluctuations around the mean for each point in time was calculated. The average current variance relationship was then binned into 30 time points (independent of the amplitude of the average mEPSC), and the data were fit with the following parabolic equation:

$$
\sigma^{2}=i l-l^{2} / N+b,
$$

where $\sigma^{2}=$ variance, $I=$ mean current, $i=$ single-channel current, $N=$ number of open channels at peak current, and $b=$ background variance. From this equation, $\gamma$ was calculated by dividing $i$ by the driving force $(-80 \mathrm{mV})$. Recordings were discarded if the parabolic fits of the current variance plots had $R^{2}<0.5$. Since $R^{2}$ values of the parabolic fits were generally $>0.75$, our estimate of $N$ (i.e., number of channels) was not affected by a skewed variance versus mean relationship (Traynelis et al., 1993; Hartveit and Veruki, 2007).

Two-photon imaging and uncaging. Simultaneous two-photon (2P) imaging and glutamate uncaging was performed using two Ti:Sapphire pulsed lasers (MaiTai-DeepSee; Spectra Physics) coupled to an Olympus MPE-1000 galvanometer scanning system. Before uncaging experiments, lasers were aligned to one another using fluorescent beads. One Ti:Sapphire laser was tuned to $810 \mathrm{~nm}$ to visualize morphology (Alexa Fluor 594), and the second laser was tuned to $720 \mathrm{~nm}$ for MNI-glutamate (MNI-Glu) uncaging. Synchronization of electrophysiological and optical equipment was accomplished using a Master- 8 pulse generator (A.M.P.I.).

Glutamate uncaging experiments were performed with $2.5 \mathrm{~mm}$ MNIglutamate trifluoroacetate (Femtonics) and tetrodotoxin supplemented to the Ringer's solution, while $0.03 \mathrm{~mm}$ Alexa Fluor 594 hydrazide (Nasalt; Invitrogen) was included in the internal recording solution. Wholecell electrophysiological recordings were performed as described above. Neurons were allowed to fill with the dye for a minimum of $10 \mathrm{~min}$ before the onset of uncaging experiments. All two-photon uncaging EPSCs were generated from proximal secondary and tertiary apical dendrites to minimize issues of space clamp. The intensity of each laser was independently controlled using two independent acousto-optic modulators. The intensity of the uncaging laser was tuned to generate a 10-20 pA AMPARmediated 2P-EPSC at a holding potential of $-70 \mathrm{mV}$ for AMPAR $-I-V$ curves. For NMDAR uncaging experiments, laser intensity was set to generate a NMDAR-mediated 2P-EPSC $<25 \mathrm{pA}$ when recorded in lowmagnesium Ringer's solution $\left(0.1 \mathrm{mM} \mathrm{Mg}^{2+}, 3 \mathrm{mM} \mathrm{Ca}^{2+}\right)$ at $-60 \mathrm{mV}$ in the presence of $0.01 \mathrm{~mm}$ NBQX (Tocris Bioscience) and $0.01 \mathrm{~mm}$ glycine. Because no particular care was taken to assure constant uncaging laser power between experiments in different neurons or slices (by normalizing for uneven light scattering at different tissue depth), we have not directly compared absolute amplitudes of 2P-EPSCs between experiments. Rather, we have compared metrics that are largely independent of laser power (i.e., rectification properties and decay kinetics: see Results). Uncaging laser power was, however, kept constant when uncaging was performed on neighboring spines and shaft regions of the same dendritic segment.

Image analysis. For spine density and spine volume measurements, two-photon image stacks of proximal apical dendrites were obtained after a minimum of $30 \mathrm{~min}$ of dye filling following whole-cell access. Image stacks were gathered in optical sections of $0.5-0.7 \mu \mathrm{m}$, with an 
A
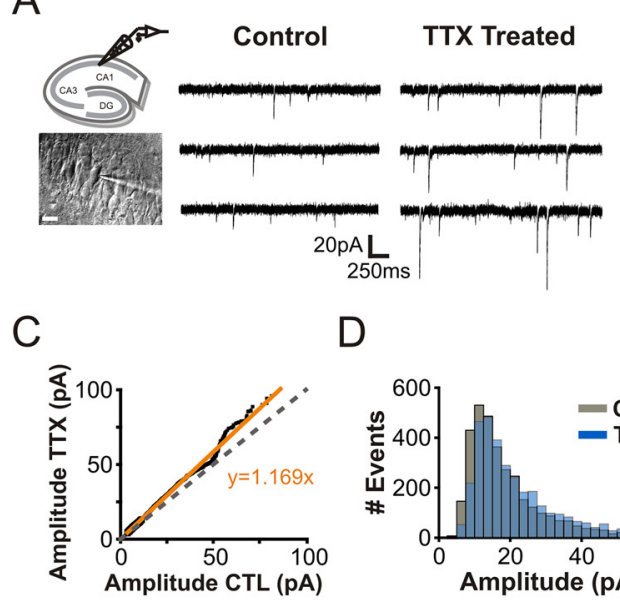

D

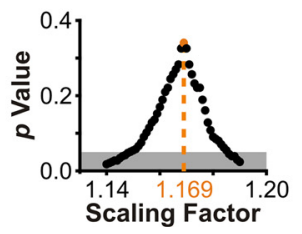

B
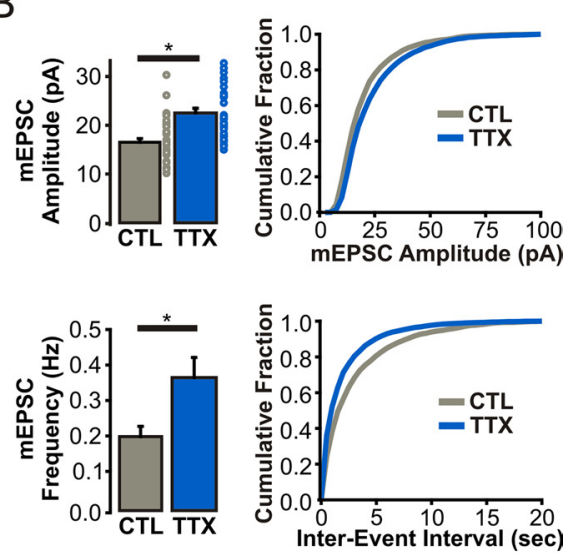

$\mathrm{E}$

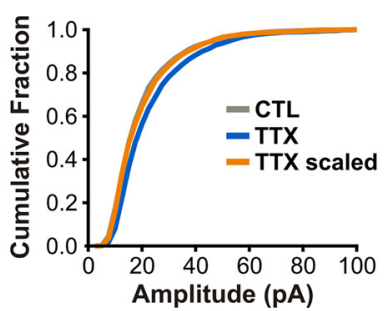

Figure 1. Multiplicative scaling of CA1 pyramidal neurons in response to prolonged TTX treatment. $A$, Current traces (membrane potential: $V_{\mathrm{m}}=-70 \mathrm{mV}$ ) of AMPAR-mediated mEPSCs (AMPAR-mEPSCs) from CA1 pyramidal neurons in control and TTX-treated hippocampal slices. B, Top, Average AMPAR-mEPSC amplitudes (for each cell) and a cumulative distribution of all AMPAR-mEPSC amplitudes (cells pooled) from control and TTX-treated neurons. Bottom, Average frequency of AMPAR-mEPSCs (for each cell) and a cumulative distribution of all AMPAR-mEPSC inter-event intervals (cells pooled) from control and TTX-treated neurons. C, Top, Rank-ordered plot of pooled AMPAR-mEPSC amplitudes ( $n=3380$ each, random subset of TTX event amplitudes) was fit through the origin with a linear function (orange line) where the slope (1.169) represents the scaling factor. Bottom, The distribution of AMPAR-mEPSC amplitudes of TTX-treated neurons was scaled iteratively by increasing scaling factors from 0.5 to 1.5 (shown in bins of 0.01 ; only $p$ values flanking the highest $p$ value are shown; $K-S$ test was used to calculate $p$ values). $\boldsymbol{D}$, Top, Amplitude distributions of AMPAR-mEPSCs recorded in control neurons (gray) and TTX-treated neurons (blue; $p<0.01, \mathrm{~K}-\mathrm{S}$ test). Bottom, Amplitude distributions of AMPAR-mEPSCs recorded in control neurons (gray) and a scaled TTX-treated distribution (orange) using the scaling factor derived in $\boldsymbol{C}(p=0.34, \mathrm{~K}-\mathrm{S}$ test). $\boldsymbol{E}$, Cumulative distribution of AMPAR-mEPSC amplitudes (as in $\boldsymbol{B}$ ) with an additional "TTX-scaled" distribution (i.e., TTX-treated AMPAR-mEPSC amplitudes divided by the scaling factor).

$X-Y$ resolution between 0.05 and $0.1 \mu \mathrm{m} /$ pixel. Spine density was calculated after manually sectioning apical dendritic reconstructions into 10 $\mu \mathrm{m}$ segments. Spine volume measurements were calculated using an intensity-based method, as previously described (Matsuzaki et al., 2001; Béique et al., 2006). In cases where spine diameters (i.e., FWHM) are shown (see Figs. 7, 8), the intensity-based method of determining spine volume was not applicable due to limitations in the images gathered (i.e., images of spines from uncaging experiments were not gathered for volume analysis, which necessitates a high-resolution image containing many large and resolvable spines for calibrating the intensity-based methods). All measurements for spine volume and spine density were generated from unprocessed images.

Analysis of dendritic complexity was achieved using Neuron Studio analysis software (Computational Neurobiology and Imaging Center, Mount Sinai School of Medicine, New York, NY). Dendritic arbors of CA1 pyramidal neurons were modeled in Neuron Studio software, and dendritic complexity measurements were extracted. The dendritic complexity metric reported is an underestimate of the total dendritic complexity, as only apical regions were included in the analysis. Complexity of Alexa Fluor 594-filled CA1 pyramidal neurons from control- and TTX-treated slices [postnatal day 7 (P7) to P8 and 9-10 DIV] were compared with age-matched neurons from acute slices (P16-P18).

Surface biotinylation assay. Organotypic slices were removed from the incubator and rapidly placed in ice-cold TBS + (in mM; 20 Tris, $0.5 \mathrm{KCl}$, $13.7 \mathrm{NaCl}, 20 \mathrm{MgCl} 2,20 \mathrm{CaCl}$, pH 7.4) containing $0.5 \mathrm{mg} / \mathrm{ml}$ SulfoNHS-SS-Biotin; Pierce/Thermo Scientific) for $20 \mathrm{~min}$. Unbound biotin was removed by washing slices with ice-cold TBS + . Slices were lysed in lysis buffer [in mM; $150 \mathrm{NaCl}, 20 \mathrm{HEPES}, 2$ EDTA, and (as percentages) 0.1 SDS and 1 Triton X-100] using a Dounce homogenizer, and sonicated $(2 \times 10$ s, $25 \%$ on a Vibra-Cell, VCX130; Sonics). The cleared supernatant was incubated with equilibrated NeutrAvidin beads (Pierce/Thermo
Scientific) at $4^{\circ} \mathrm{C}$ for $1.5 \mathrm{~h}$. Beads were washed six times in a TBS solution with $0.05 \%$ SDS, and bound protein was eluted with elution buffer [in $\mathrm{mm} ; 50$ Tris- $\mathrm{HCl}, 1 \mathrm{DTT}$, and (as percentage) $2 \mathrm{SDS}$ ] and boiled at $100^{\circ} \mathrm{C}$ for $10 \mathrm{~min}$.

Equal concentrations of internal and surface proteins were loaded on SDS-PAGE, and Western blot was performed with the following antibodies: anti-GluN1 (1:3000, mouse monoclonal) and anti-glycine receptor (GlyR; 1:1000, mouse monoclonal) from Synaptic Systems; antiGluN2A (1:1500, rabbit polyclonal), anti-GluN2B (1:1500, rabbit polyclonal), anti-GluA1 (1:1000 rabbit monoclonal) from Millipore; anti-GluA2 (1:2000, rabbit polyclonal) from Pierce Antibodies; and anti- $\beta$-actin (1: 6000 , mouse monoclonal) from Genscript. The chemiluminescent intensities were recorded using an Odyssey Fc Imaging System (LI-COR). Quantitative analyses were performed by determining the intensity of each band with Image Studio software (LI-COR).

\section{Results}

Enhanced AMPAR conductance during multiplicative homeostatic synaptic strengthening in CA1 pyramidal neurons

We first sought to recapitulate key features of HSP in an organotypic hippocampal slice preparation. Consistent with previous studies, CA1 pyramidal neurons from hippocampal slices incubated for 3-4 d with TTX ( $1 \mu \mathrm{M})$ exhibited a robust increase in the amplitude (CTL: $16.51 \pm 0.98 \mathrm{pA}, n=35$ cells; TTX: $22.50 \pm$ 0.74 pA, $n=33$ cells; $p<0.01$; Tyler and Pozzo-Miller, 2003; Kim and Tsien, 2008; Arendt et al., 2013) and frequency of AMPARmediated mEPSCs (CTL: $0.20 \pm 0.03 \mathrm{~Hz}$; TTX: $0.36 \pm 0.06 \mathrm{~Hz}$; $p<0.01)$ as determined by whole-cell electrophysiological re- 
A
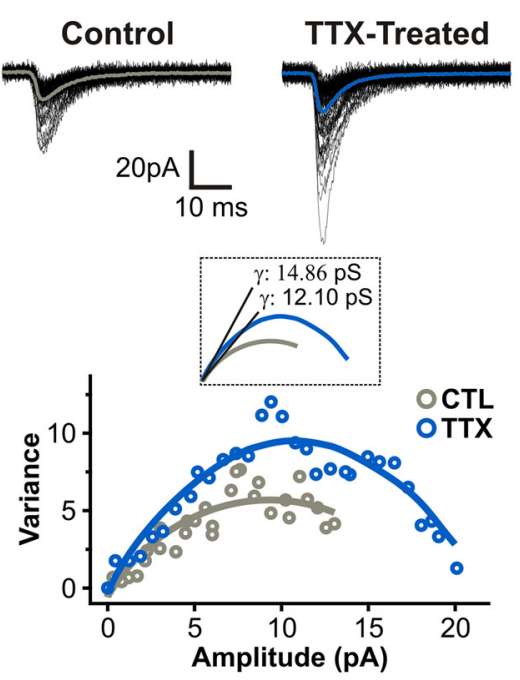

$\mathrm{D}$
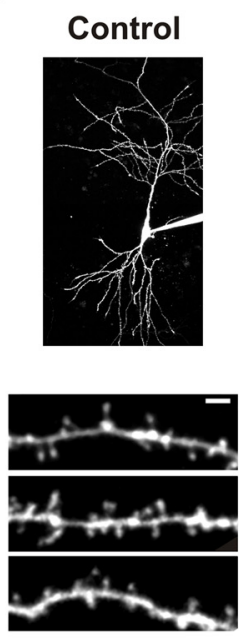

B
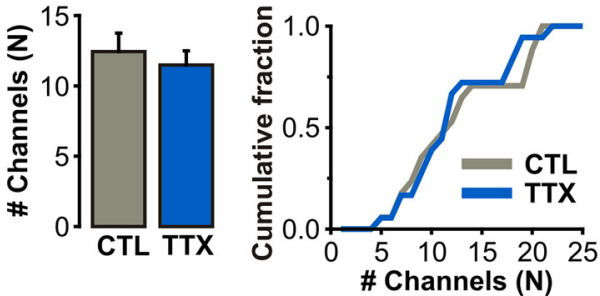

C

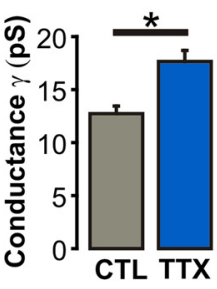

$\mathrm{E}$
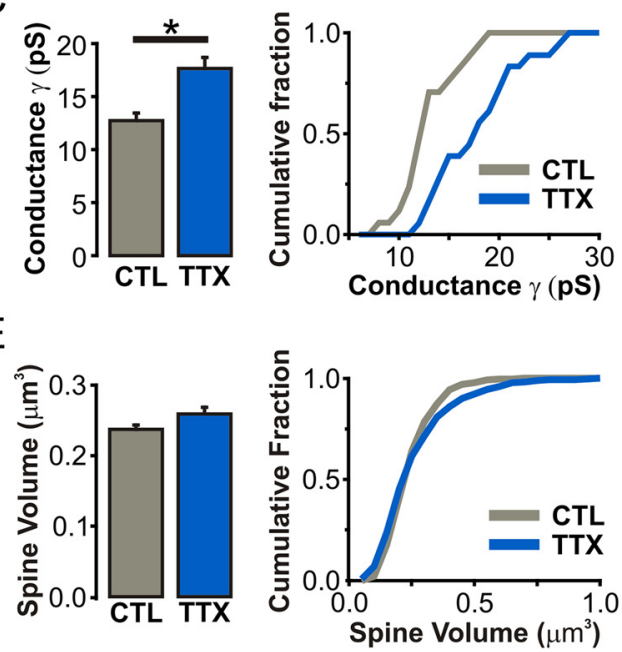

$\mathrm{F}$

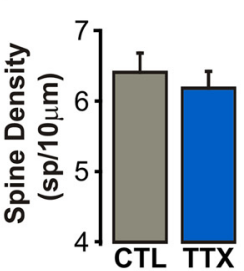

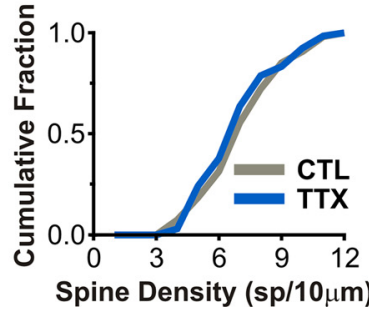

Figure 2. Recruitment of higher-conductance synaptic AMPARs following prolonged TTX treatment. $A$, Top, Traces of AMPAR-mEPSC from a single voltage-clamp recording $\left(V_{\mathrm{m}}=-70 \mathrm{mV}\right)$ of a control and TTX-treated CA1 pyramidal neuron. Bottom, Current-variance plots from peak-scaled nonstationary noise analysis of AMPAR-mEPSCs (see Materials and Methods). Inset, Initial slope of the parabolic fit was used to calculate the mean AMPAR channel conductance $(\gamma)$. B, Number of channels $(N)$ open at the peak of cell-averaged AMPAR-mEPSC. Cumulative distribution of $N$ is plotted for each condition. C, Mean AMPAR $\gamma$ for AMPAR-mEPSCs recorded from CTL and TTX-treated neurons. Cumulative distribution of $\gamma$ is plotted for each condition. D, 2P images of CA1 pyramidal neurons filled with Alexa Fluor $594(30 \mu \mathrm{M})$. All images were taken $>20 \mathrm{~min}$ after gaining whole-cell access to allow adequate intracellular dye loading. Scale bar, $2 \mu \mathrm{m}$. $\boldsymbol{E}$, Volumes of dendritic spines on apical dendrites of control and TTX-treated neurons calculated using an intensity-based method (see Materials and Methods). Cumulative distribution of spine volumes for each condition is plotted. $\boldsymbol{F}$, Average density of dendritic spines on apical dendrites of filled CA1 pyramidal neurons. Cumulative distribution of spine densities sampled in $10 \mu \mathrm{m}$ dendritic segments.

cordings (Fig. 1A,B). A key feature of homeostatic synaptic strengthening is that the amplitude distribution of AMPARmEPSCs is scaled by a single common factor, likely reflecting cell-wide synaptic changes whereby each synapse scales proportionally to its original weight (Turrigiano et al., 1998; Lee et al., 2013). To establish whether such multiplicative scaling occurs in our experimental paradigm, we derived a scaling factor using two independent analytical methods (Turrigiano et al., 1998; Kim et al., 2012). First, we plotted the rank-order relationship of 3380 randomly selected AMPAR-mediated mEPSC amplitudes from both control and TTX-treated neurons (Fig. 1C). As true multiplicativity necessitates the exclusion of additive components (Kim et al., 2012), the scaling factor was obtained from the slope of the linear relationship through the origin of the rank-ordered plot. Consistent with multiplicative HSP, the distribution of mEPSC amplitudes from TTX-treated neurons overlapped well with the control distribution when divided (or "scaled") by this scaling factor [scaling factor $=1.169 ; p=0.34$, Kolmogorov-
Smirnov (K-S) test; Fig. 1D,E]. Using a separate approach, we iteratively tested 1000 scaling factors ranging from 0.5 to 1.5 (Fig. 1C; see Materials and Methods; Kim et al., 2012). We found perfect agreement in the scaling factors obtained from these different tests, indicating that prolonged TTX treatment induced multiplicative scaling of synaptic AMPAR function in our experimental paradigm.

We then performed a peak-scaled nonstationary noise analysis of AMPAR-mediated mEPSCs to determine whether prolonged network silencing alters the unitary properties of AMPAR-mediated synaptic transmission (Fig. 2A; Hartveit and Veruki, 2007). Whereas the average number of synaptic AMPARs was unchanged (CTL: $12.44 \pm 1.31, n=17$ cells; TTX: $12.72 \pm$ $0.72, n=18$ cells; $p=0.33$; Fig. $2 B$ ), we found that the mean AMPAR channel conductance was enhanced in TTX-treated neurons (CTL: $12.01 \pm 1.12$ pS; TTX: $17.65 \pm 1.05$ pS; $p<0.01$; Fig. $2 C$ ). These changes in postsynaptic AMPAR function were not accompanied by alterations in the volume (CTL: $0.24 \pm 0.01$ 
A
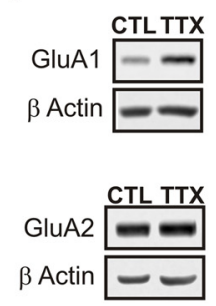

C

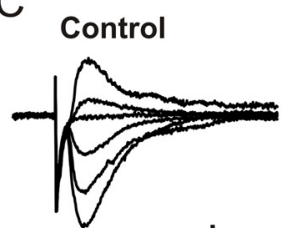

$25 \mathrm{pA}$

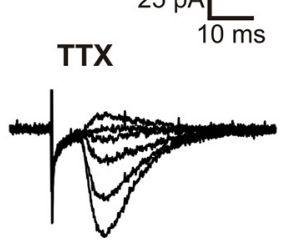

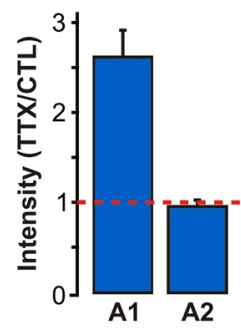
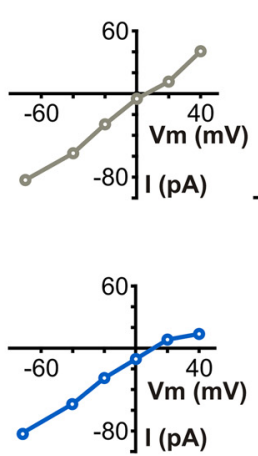

B

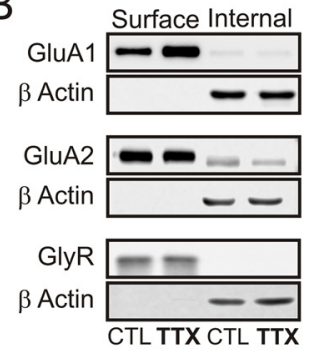

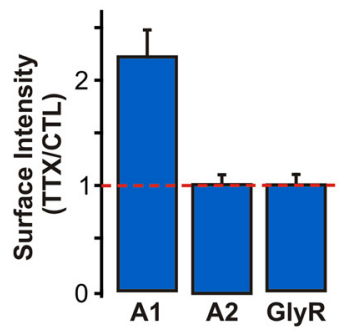

D

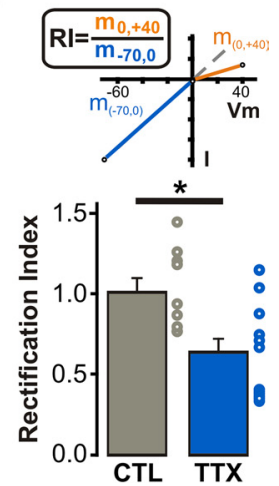

Figure 3. Increased surface expression of GluA1 and the emergence of inwardly rectifying AMPARs at SC synapses following prolonged TTX treatment. $\boldsymbol{A}$, Representative Western blots and quantification for the change in AMPA receptor subunit expression, plotted as a TTX/CTL ratio of band intensity, in hippocampal lysates from control and TTX-treated slices. All bands were normalized to $\beta$-actin before calculating the TTX/CTL ratio. $\boldsymbol{B}$, Representative Western blots of biotinylated (surface) and nonbiotinylated (internal) fractions from control and TTX-treated hippocampal slices. Relative surface expression of AMPA and GlyR subunits from control and TTX-treated slices, plotted as a TTX/CTL ratio of band intensity. C, I-V relationship of evoked AMPAR-EPSCs. Left, Current traces at different holding potentials ( -70 to $+40 \mathrm{mV}$; with $100 \mu \mathrm{m}$ intracellular spermine). Middle, Corresponding $/-V$ curves from individual control and TTX-treated neurons. Right, Average $I-V$ relationship of evoked AMPAR-EPSCs from control and TTX-treated neurons. $\boldsymbol{D}$, Rectification indices for control and TTX-treated neurons in $\boldsymbol{B}$, computed as the ratio of the slope $(\mathrm{m})$ of the outward portion of the $I-V$ curve over that of the inward portion ( $p<0.01$, unpaired Student's $t$ test).

$\mu \mathrm{m}^{3}, n=227$ spines, 8 cells; TTX: $0.26 \pm 0.01 \mu \mathrm{m}^{3}, n=271$ spines, 8 cells; $p=0.07, \mathrm{~K}-\mathrm{S}$ test; Fig. $2 E$ ) or density of dendritic spines (CTL: $6.41 \pm 0.27$ spines/10 $\mu \mathrm{m}$; TTX: $6.18 \pm 0.24$ spines $/ 10 \mu \mathrm{m} ; p=0.98, \mathrm{~K}-\mathrm{S}$ test; Fig. $2 F$ ), as determined by two-photon imaging of neurons filled with Alexa Fluor 594. In principle, this increased AMPAR conductance could be mediated by post-translational modifications to AMPARs, or by changes in the pore-forming subunit composition of AMPARs. Although there is support for the latter possibility in dissociated neuronal cultures (Thiagarajan et al., 2005; Sutton et al., 2006; Groth et al., 2011), it is unclear whether the subunit composition of AMPARs is homeostatically regulated in CA1 pyramidal neurons from organotypic slices. We therefore sought to determine whether the subunit composition of synaptic AMPARs at CA1 synapses is altered following prolonged TTX treatment.

\section{Homeostatic upregulation of synaptic GluA2-lacking AMPARs}

Western blot analyses of organotypic hippocampal slice lysates were performed to first determine whether changes in AMPAR subunit expression occurred in response to prolonged inactivity. TTX-induced inactivity caused an increase in the expression of GluA1, but not GluA2, AMPAR subunits (TTX/CTL ratio: GluA1, $2.62 \pm 0.30, n=3$; GluA2, $0.96 \pm 0.07, n=4$; Fig. $3 A$ ). Moreover, surface biotinylation experiments from these slices revealed a robust homeostatic enhancement of surface GluA1 with no change in the amount of surface GluA2 or glycine receptor subunits (TTX/CTL ratio: GluA1, $2.22 \pm 0.26, n=9$; GluA2, $1.03 \pm 0.07, n=10$; GlyR, $1.01 \pm 0.10, n=7$; Fig. $3 B)$. These biochemical findings, combined with the increased AMPAR conductance detected by nonstationary noise analysis (Fig. 2C), raise the possibility that prolonged inactivity triggers a specific upregulation of GluA2-lacking AMPARs. Since this hypothesis is consistent with some (Ju et al., 2004; Thiagarajan et al., 2005; Sutton et al., 2006; Aoto et al., 2008; Groth et al., 2011) but not all previously reported evidence (O'Brien et al., 1998; Gainey et al., 2009; Anggono et al., 2011) using broadly analogous manipulations in dissociated neuronal cultures, we further investigated this possibility in our hippocampal slice paradigm using biophysical and pharmacological methods.

AMPARs containing GluA2 subunits exhibit linear $I-V$ relationships, while those lacking GluA2 display inward rectification due to a pore block by intracellular polyamines at depolarized potentials (Bowie and Mayer, 1995). We thus used this biophysical signature to test the hypothesis that HSP involves an upregulation of GluA2-lacking AMPARs. We calculated rectification indices for $I-V$ curves constructed from pharmacologically isolated AMPAR-mediated eEPSCs at Schaffer collateral (SC) synapses in the presence of intracellular spermine $(100 \mu \mathrm{M})$. As expected, control AMPAR-eEPSCs displayed linear $I-V$ relationships (rectification index: $1.01 \pm 0.09, n=13$ cells; Fig. $3 C, D$ ), consistent with the presence of predominantly GluA2-containing AMPARs at these synapses (Béïque and Huganir, 2009; Lu et al., 2009). In contrast, we detected a strong voltage-dependent block of AMPAR-eEPSCs in TTX-treated neurons (rectification index: TTX, $0.64 \pm 0.11, n=8$ cells; Fig. $3 C, D$ ), supporting the presence of synaptic GluA2-lacking AMPARs in response to inactivity.

We then measured the sensitivity of AMPAR-eEPSCs to the selective antagonist of GluA2-lacking AMPARs, NASPM (20 $\mu \mathrm{M})$. Bath administration of NASPM robustly reduced the amplitude of AMPAR-eEPSCs recorded from TTX-treated neurons, whereas AMPAR-eEPSCs from control slices were 
A Evoked EPSCs
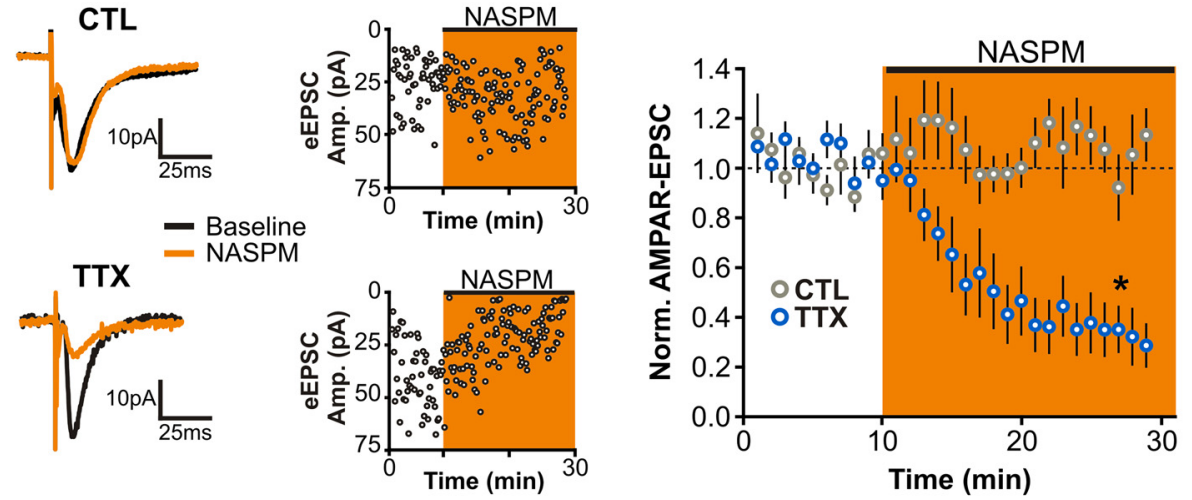

B

Spontaneous EPSCs
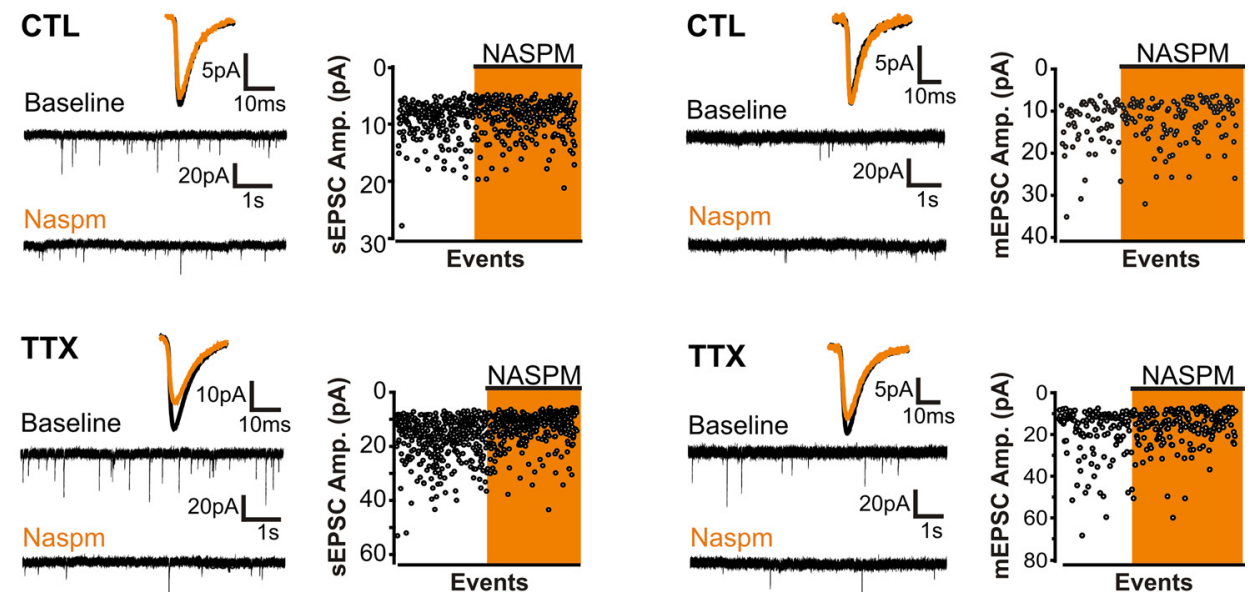

C

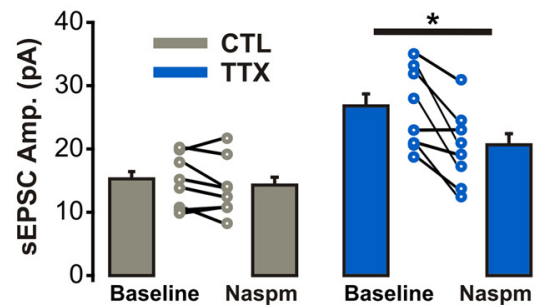

$\mathrm{E}$

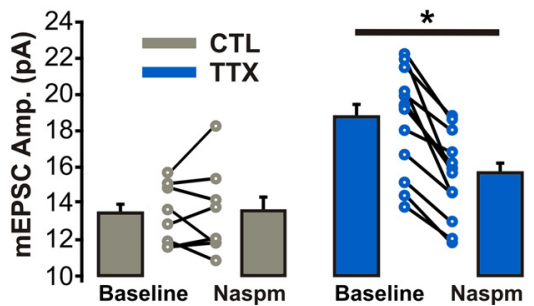

Figure 4. Synaptic incorporation of GluA2-lacking AMPARs in CA1 pyramidal neurons following prolonged TTX treatment. $A$, Left, Representative traces and event amplitude scatter plots of evoked AMPAR-EPSCs before and after NASPM administration $(20 \mu \mathrm{M})$. Right, Normalized average amplitude of evoked AMPAR-EPSCs. $\boldsymbol{B}$, Current traces and event amplitude scatter plots of spontaneous AMPAR-EPSCs (i.e., no TTX during recording; AMPAR-sEPSC) before (baseline) and 15-20 min after onset of NASPM (20 $\mu \mathrm{m}$ ) administration. C, Average AMPAR-sEPSC amplitudes before (baseline) and 15-20 min after NASPM administration. $\boldsymbol{D}$. Current traces and event amplitude scatter plots of AMPAR-mEPSCs (i.e., recorded in TTX) before and 15-20 min after onset of NASPM administration. $\boldsymbol{E}$, Average AMPAR-mEPSC amplitudes before (baseline) and 15-20 min after NASPM administration.

unaffected (NASPM inhibition: CTL, $-6.15 \pm 7.95 \%, n=7$ cells, $p=0.47$; TTX, $69 \% \pm 9.48 \%, n=8$ cells, $p<0.01$; Fig. $4 A$ ). To sample a larger population of synapses, we also measured the NASPM sensitivity of pharmacologically isolated spontaneous and miniature AMPAR-EPSCs [spontaneous EPSCs (sEPSCs) and mEPSCs]. In agreement with the results outlined above, NASPM did not affect the amplitude of control sEPSCs (from $14.85 \pm 1.50$ to $13.98 \pm 1.59$ pA in NASPM; $p=0.12 ; n=8$ cells) or mEPSCs (from $13.41 \pm 0.59$ to $13.53 \pm 0.86 \mathrm{pA}$ in NASPM; $p=0.82 ; n=8$ cells), but significantly reduced the amplitude of these events recorded from TTX-treated neurons (sEPSCs: from $26.53 \pm 2.26$ to $19.85 \pm$ 2.13 pA in NASPM, $p<0.01$; mEPSCs: from $18.71 \pm 0.79$ to $15.62 \pm 0.64 \mathrm{pA}$ in NASPM, $p<0.01$; Fig. $4 B-E)$. Together, these data are consistent with the expression of synaptic GluA2-lacking AMPARs during HSP.

Previous studies have demonstrated that synaptic strengthening during LTP is mediated by an increase in synaptic AMPAR number and is accompanied by robust dendritic spine enlargement (Matsuzaki et al., 2004; Harvey and Svoboda, 2007). Remarkably, we found that the synaptic strengthening during HSP was not accompanied by changes in the number of AMPARs at synapses (Fig. 2B), nor in the volume of dendritic spines (Fig. 2E). Rather, our biochemical, biophysical, and pharmacological data strongly suggest that the postsynaptic manifestation of HSP is expressed in part through the direct replacement of synaptic GluA2-containing AMPARs with higher-conductance GluA2lacking AMPARs. 
A

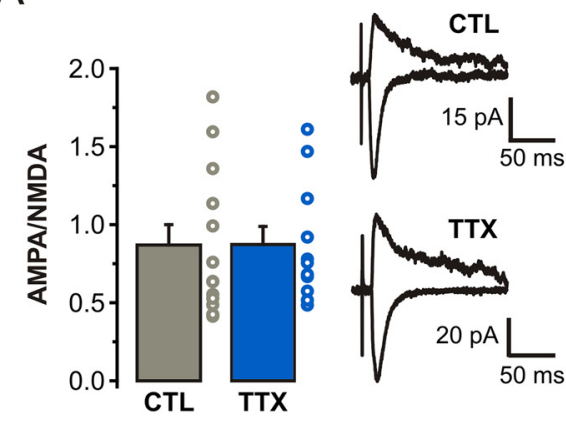

D

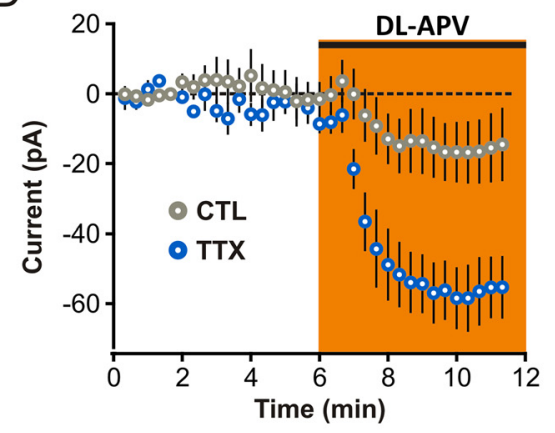

$\mathrm{E}$

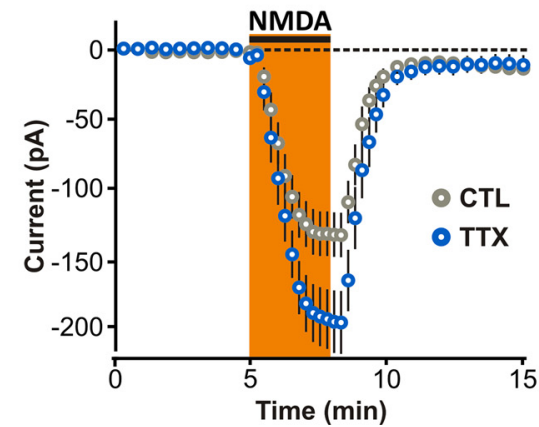

B
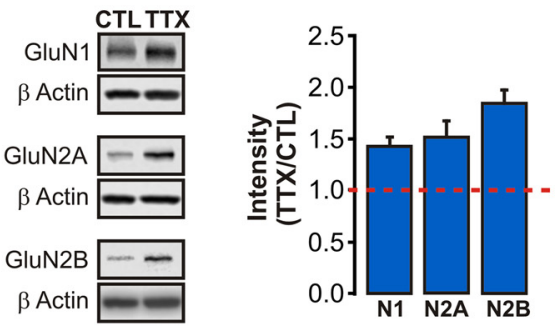

C
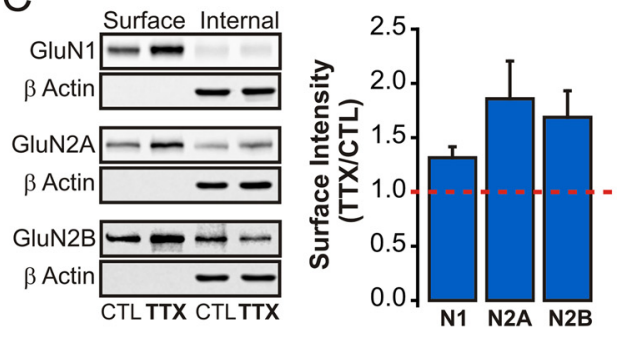

$\mathrm{F}$

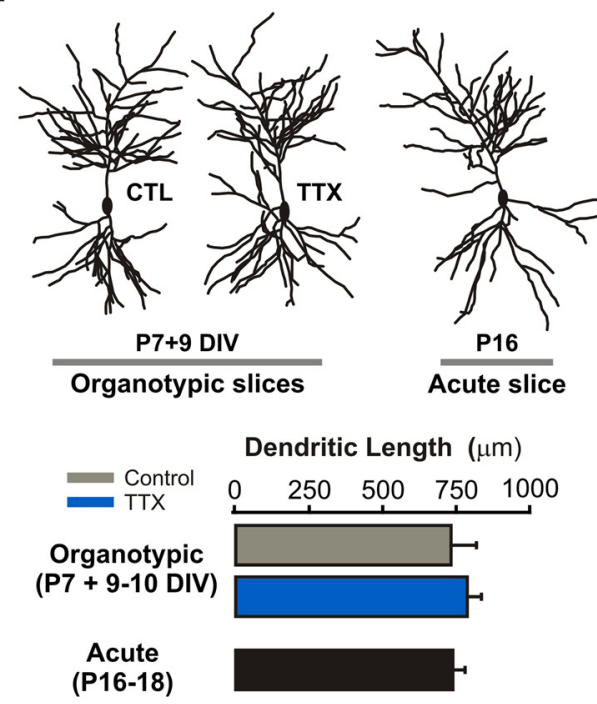

Figure 5. Homeostatic upregulation of surface NMDARs in CA1 pyramidal neurons in response to prolonged TTX treatment. A, AMPA/NMDA ratio of evoked EPSCS (see Materials and Methods). $B$, Representative Western blots and quantification of changes in NMDAR subunit expression, plotted as a TTX/CTL ratio of band intensity, in hippocampal lysates of control and TTX-treated slices. All bands were normalized to $\beta$-actin before calculating the TTX/CTL ratio. C, Representative Western blots of biotinylated (surface) and nonbiotinylated (internal) fractions from control and TTX-treated slices. Relative surface expression of NMDA receptor subunits between control and TTX-treated slices plotted as a TTX/CTL ratio of band intensity. $\boldsymbol{D}$, Change in holding current induced by bath administration of $50 \mu \mathrm{m}$ DL-APV while holding the neurons at $+40 \mathrm{mV}(p<0.05$, unpaired Student's $t$ test). These experiments were performed with NBQX, picrotoxin, and TTX in the Ringer's solution. $E$, Amplitude of the inward current induced by bath administration of NMDA $\left(5 \mu \mathrm{m} ; V_{\mathrm{m}}=-60 \mathrm{mV}\right.$ in $\left.0.1 \mathrm{~mm} \mathrm{Mg}{ }^{2+}\right)$. All NMDA bath administration experiments were performed with NBQX, picrotoxin, and TTX in the Ringer's solution. $F$, 2P images of filled CA1 pyramidal neurons were reconstructed using Neuron Studio software (see Materials and Methods). Dendritic length (in micrometers) is plotted for CA1 pyramidal neurons from TTX-treated or control organotypic slices (P7 and 9-10 DIV) and from age-matched neurons from acute slices (P16 -P17 animals; $n=$ 10, 12, and 9 neurons for control, TTX-treated, and acute slices, respectively).

\section{Homeostatic switch in synaptic NMDAR} subunit composition

The dynamic nature of NMDAR trafficking and targeting behavior at rest, during postnatal development, and during Hebbian plasticity has gained considerable appreciation over the past 2 decades (Lau and Zukin, 2007). In part because HSP has overwhelmingly been studied in dissociated neuronal cultures, a preparation that does not lend itself with ease to the study of NMDAR function, the homeostatic regulation of NMDARs has been far less extensively studied than that of AMPARs (PérezOtaño and Ehlers, 2005). To determine whether alterations in NMDAR function accompanied the homeostatic enhancement in AMPAR function outlined above, we evoked EPSCs while holding neurons at -70 and $+40 \mathrm{mV}$ to compute the ratio of
AMPAR and NMDAR contributions to SC synapse function (see Materials and Methods). We found that the ratio of AMPA to NMDA receptor components of eEPSCs was not altered by prolonged inactivity (CTL: $0.87 \pm 0.13, n=13$ cells; TTX: $0.87 \pm$ $0.12, n=12$ cells; $p=0.98$; Fig. $5 A$ ), consistent with previous findings in both neuronal cultures and organotypic slices younger than those used here (Watt et al., 2000; Arendt et al., 2013). Since AMPAR function was significantly enhanced during HSP in our experimental conditions (Fig. $1 B$ ), this finding suggests a concomitant upregulation of both synaptic NMDA and AMPAR function during HSP. In line with this notion, Western blot analysis of hippocampal slice lysates (Fig. $5 B$ ) and surface biotinylation experiments (Fig. $5 C$ ) revealed an increase in the expression and surface delivery of all three major NMDAR subunits 
found in the hippocampus in TTX-treated slices (TTX/CTL ratio for hippocampal lysates: GluN1, $1.43 \pm 0.09, n=4$; GluN2A, $1.52 \pm 0.16, n=6$; GluN2B, $1.85 \pm 0.13$, $n=3$; Fig. $5 B$; TTX/CTL ratio for biotinylated samples: GluN1, $1.31 \pm 0.10, n=10$; GluN2A, $1.86 \pm 0.35, n=8$; GluN2B, $1.69 \pm 0.24, n=15$; Fig. $5 C$ ).

To further establish whether NMDAR function is homeostatically regulated in CA1 pyramidal neurons, we gathered two complementary electrophysiological readouts of NMDAR function. First, we reasoned that an upregulation of surface NMDARs could be revealed by examining the degree of tonic activation of these receptors by ambient levels of extracellular glutamate (Sah et al., 1989). To this end, we monitored changes in whole-cell current of CA1 pyramidal neurons induced by bath administration of the NMDAR antagonist DL-APV ( $50 \mu \mathrm{M}$; see Materials and Methods). NMDAR blockade in control neurons induced a small but highly reproducible change in holding current (15.48 $\pm 10.86 \mathrm{pA}, n=5$ cells), thus revealing the presence of an ambient glutamate tone in organotypic hippocampal slices (Fig. 5D). Interestingly, the magnitude of this tonic current was more than three times greater in TTX-treated slices (56.15 $\pm 9.51 \mathrm{pA}, n=7$ cells) compared with that seen in controls. In principle, this difference could reflect an upregulation of surface NMDARs, an alteration in the regulation of ambient extracellular glutamate concentration, or a combination of both. To directly measure NMDAR function, we next monitored the whole-cell response to bath administration of NMDA ( $5 \mu \mathrm{M}$ for $3 \mathrm{~min}$ ) and found that NMDA induced significantly larger whole-cell currents in TTX-treated neurons compared with control (CTL: $128.69 \pm 15.44 \mathrm{pA}, n=16$ cells; TTX: $198.98 \pm 21.42 \mathrm{pA}, n=16$ cells; $p<0.05$; Fig. $5 E)$. This enhancement was likely not due to an overall greater membrane surface area in TTX-treated neurons, since the dendritic arborization between control and TTX-treated neurons was not different (CTL: $732.36 \pm$ $86.43 \mu \mathrm{m}, n=10$ cells; TTX: $787.48 \pm 48.56 \mu \mathrm{m}, n=12$ cells; $p=$ 0.56 ; Fig. $5 F$ ). These functional and morphological measurements aligned well with our biochemical data (Fig. $5 B, C$ ), and together they demonstrate that prolonged inactivity induced a robust upregulation of surface NMDAR expression in CA1 pyramidal neurons.

During Hebbian LTP, synaptic NMDARs undergo a rapid switch in subunit composition, from predominantly NR2Bcontaining toward NR2A-containing NMDARs (Bellone and Nicoll, 2007). We therefore next wondered about the degree of mechanistic commonality between Hebbian and homeostatic synaptic strengthening and asked whether the subunit composition of synaptic NMDARs is likewise regulated during homeostatic synaptic plasticity. To this end, we probed the subunit composition of synaptic NMDARs by first analyzing the kinetics of pharmacologically isolated NMDAR-eEPSCs from SC synapses and found that TTX-treated neurons exhibited NMDAR-
eEPSCs with faster decay kinetics compared with control $\left(\tau_{\mathrm{w}}\right.$ : CTL, $366.03 \pm 19.72 \mathrm{~ms}, n=15$ cells; TTX, $315.44 \pm 15.16 \mathrm{~ms}$, $n=18$ cells; $p<0.05$; Fig. $6 A$ ). Based on the well characterized subunit dependence of NMDAR kinetics (Vicini et al., 1998), these results suggest that prolonged inactivity led to synaptic enrichment of GluN2A-containing NMDARs. We further tested this possibility pharmacologically by measuring the sensitivity of NMDAR-eEPSCs to the GluN2B-containing NMDAR antagonist ifenprodil $(3 \mu \mathrm{M})$ and found that NMDAR-eEPSCs recorded from TTX-treated neurons were significantly less sensitive to ifenprodil than interleaved controls (ifenprodil inhibition: CTL, $56.67 \pm 4.80 \%, n=12$ cells; TTX, $37.95 \pm 3.65 \%, n=16$ cells; $p<0.01$; Fig. $6 B$ ). Thus, despite a robust upregulation of all three major NMDAR subunits at the plasma membrane, we found that GluN2A-containing NMDARs are preferentially stabilized at synapses during HSP.

\section{Subcellular distribution of AMPAR and NMDAR subtypes following network silencing}

The trafficking, targeting, and stabilization of glutamate receptors at synapses occurs through a number of highly regulated intracellular and extracellular interactions (Shepherd and Huganir, 2007). An emerging model of synaptic AMPAR recruitment involves the trapping of freely diffusing extrasynaptic surface receptors as they enter the synaptic compartment (Opazo 
A

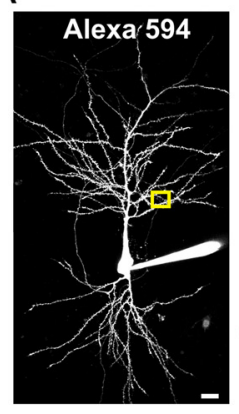

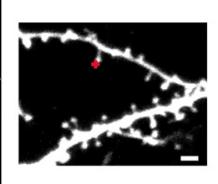

B
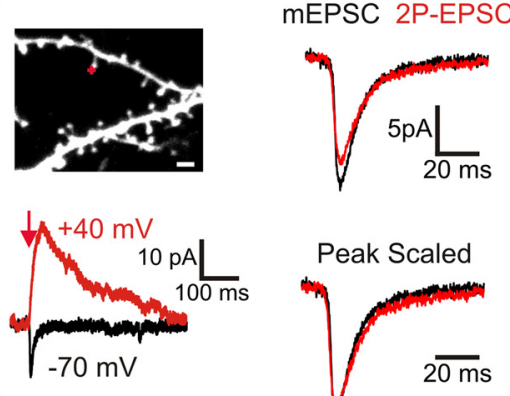

C
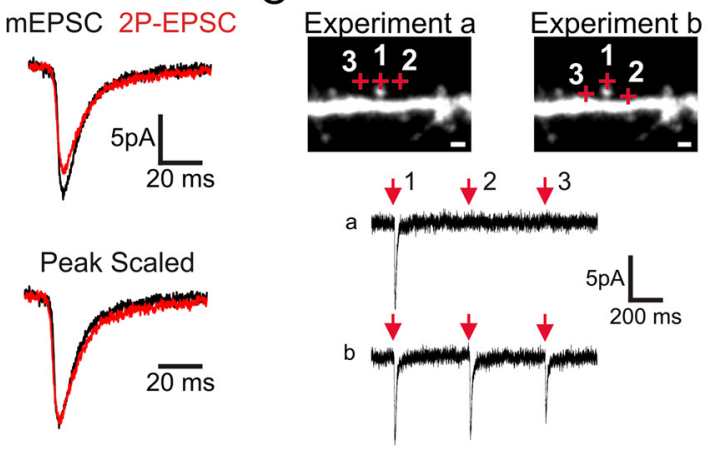

D

Control
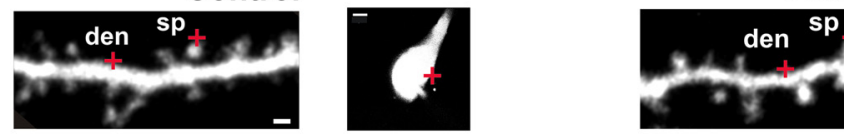

TTX Treated
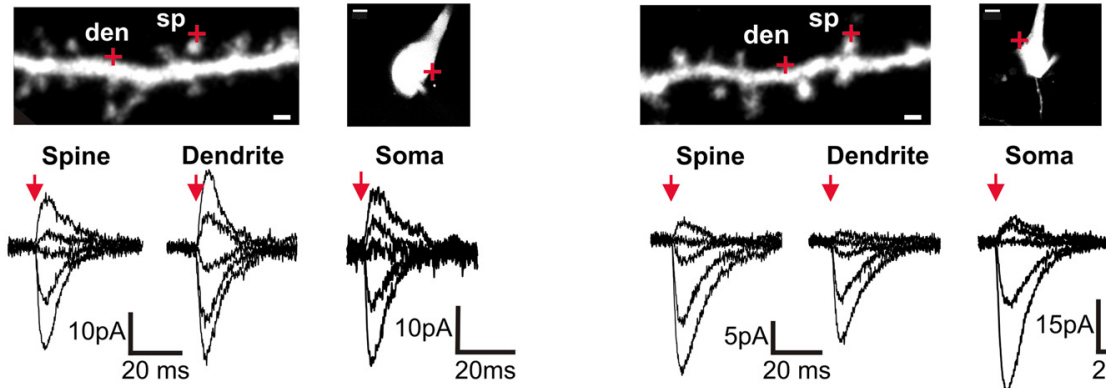

Soma

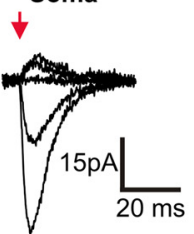

$E$

Spine

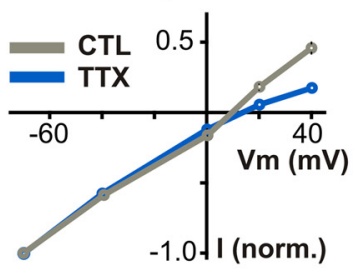

Dendrite

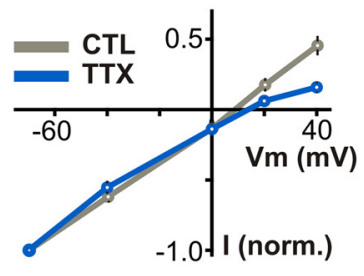

G

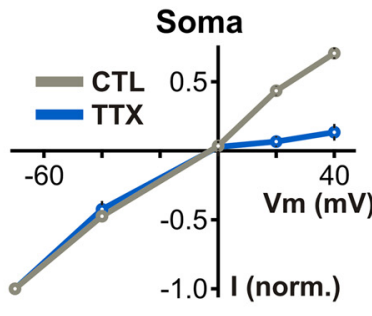

$\mathrm{H}$
$\mathrm{F}$

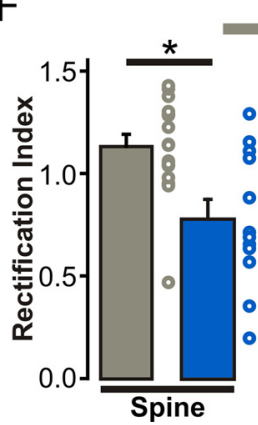

CTL TTX

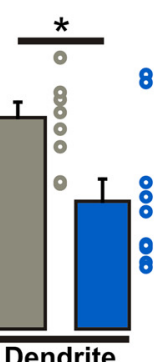

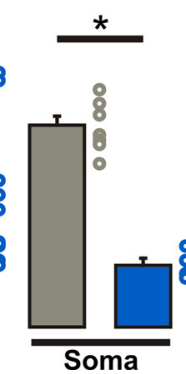
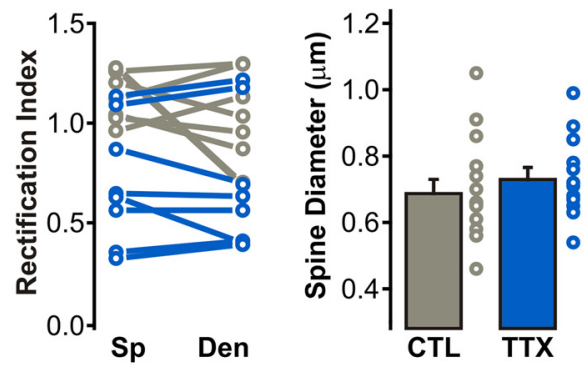

Figure 7. Cell-wide homeostatic upregulation of GluA2-lacking AMPARs in response to prolonged TTX treatment. A, Left, $2 \mathrm{P}$ image of a control CA1 pyramidal neuron filled with Alexa Fluor 594 to visualize dendritic morphology. Scale bar, $15 \mu \mathrm{m}$. Right, Enlarged view of an apical dendritic segment with red crosshairs illustrating the site of $2 \mathrm{P}$ glutamate uncaging (1 ms at $720 \mathrm{~nm})$. Scale bar, $2 \mu \mathrm{m}$. At $-70 \mathrm{mV}$, glutamate uncaging elicits a postsynaptic AMPAR-mediated response, whereas at $+40 \mathrm{mV}$ uncaging of glutamate also activates longer-decaying NMDAR EPSCs. $\boldsymbol{B}$, Top, AMPAR-2P-EPSCs can be generated to match the amplitude of AMPAR-mEPSCs from the same recording. Bottom, Peak scaling of the average traces of AMPAR-2P-EPSCs and AMPAR-mEPSCs reveals a similar rise and decay time course. C, A set of control experiments whereby three uncaging pulses (separated by $500 \mathrm{~ms}$ ) were elicited at each of the three points illustrated with red crosshairs. In experiment $b$, the uncaging positions of sites 2 and 3 were brought closer to the dendrite to elicit a response mediated by extrasynaptic receptors. Scale bars, $1 \mu \mathrm{m}$. $D, I-V$ relationship of AMPAR-2P-EPSCs generated at distinct subcellular locations. Top, 2 P images of secondary apical dendritic segment show sites of glutamate uncaging (red crosshairs). Scale bars: dendrite images, $1 \mu \mathrm{m}$; soma images, $5 \mu \mathrm{m}$. Bottom, AMPAR-2P-EPSCs at different holding potentials ( $-70 \mathrm{to}+40 \mathrm{mV}$; with $100 \mu \mathrm{m}$ intracellular spermine) with red arrow depicts the timing of the $1 \mathrm{~ms}$ uncaging pulse. $\boldsymbol{E}$, Average $I-V$ curves of 2P-EPSCs from each subcellular location in both control and TTX conditions. $\boldsymbol{F}$, Rectification indices for all spine, dendritic, and somatic $I-V$ curves presented in $\boldsymbol{E}(p<$ 0.01; unpaired Student's $t$ test). $G$, Rectification indices of 2P-EPSCs generated from pairs of spine and neighboring $(<5 \mu \mathrm{m}$ ) extrasynaptic shaft regions. $\boldsymbol{H}$, Diameters (FWHM) of all dendritic spines probed for AMPAR-2P-EPSC $1-V$ relationships.

and Choquet, 2011), and an analogous diffusional trapping mechanism has also been described for NMDARs (Groc et al., 2006; Bard et al., 2010). Moreover, the functional enhancement of AMPAR transmission during LTP is highly dependent on this reserve pool of nonsynaptic receptors (Makino and Malinow, 2009; Granger et al., 2013). Although our electrophysiological data outlined above clearly demonstrate that the subunit composition of synaptic AMPARs (Figs. 3, 4) and NMDARs (Fig. 6) are 
altered during HSP, it is unclear whether these changes reflect synapse-specific regulation or rather diffuse, cell-wide, changes in surface glutamate receptor expression. To specifically address this issue, we took advantage of subunit-specific biophysical signatures of AMPAR and NMDAR subtypes in combination with the ability afforded by 2P-uncaging of MNI-Glu to activate glutamate receptors at defined subcellular compartments (Fig. 7A-C).

To determine the spatial extent of GluA2-lacking AMPAR surface expression, we analyzed the $I-V$ relationship of 2P glutamate uncaging-evoked AMPARmediated EPSCs (AMPAR-2P-EPSCs) at dendritic spines and nearby $(<5 \mu \mathrm{m})$ extrasynaptic shaft regions of secondary and tertiary proximal apical dendrites. In agreement with a previous study in neuronal cultures (Béique et al., 2011), uncaging of MNI-glutamate onto spines and onto extrasynaptic shaft and somatic regions of control neurons yielded AMPAR-2PEPSCs exhibiting linear $I-V$ relationships, although rectifying currents were occasionally encountered (rectification index: spine, $1.10 \pm 0.06, n=16$; dendrite, $1.01 \pm 0.08$, $n=9$; soma, $0.98 \pm 0.04, n=6$; Fig. $7 D-F$ ). Thus, GluA2-containing AMPARs appear to dominate both synaptic and extrasynaptic regions of control CA1 neurons. Consistent with the upregulation of synaptic GluA2-lacking AMPARs (i.e., synaptically evoked EPSCs; Figs. 3, 4) in response to prolonged inactivity, we observed strong inwardly rectifying AMPAR-2P-EPSCs when uncaging pulses were directed onto the tips of dendritic spines in TTX-treated neurons (rectification index: $0.76 \pm 0.09, n=12$ spines; Fig. $7 D-F$ ). The changes in the rectifying properties of $2 \mathrm{P}-$ EPSCs from spines between control and TTX-treated neurons could not be accounted for by an experimental bias toward morphologically dissimilar spines in the treatment groups $(p=0.47$; Fig. $7 H)$. Interestingly, inwardly rectifying AMPAR-2P-EPSCs were also detected when glutamate was uncaged onto dendritic shafts and somatic regions of TTX-treated neurons (rectification index: dendrite, $0.61 \pm 0.11, n=10$; soma, $0.30 \pm 0.04, n=4$; Fig. $7 D-F)$. Together, our data suggest that prolonged inactivity drives a robust cell-wide expression of GluA2-lacking AMPARs at both synaptic and extrasynaptic regions of CA1 pyramidal neurons.

We last investigated the subcellular distribution of GluN2Aand GluN2B-containing NMDARs during HSP by analyzing the decay kinetics of NMDAR-2P-EPSCs elicited at either dendritic spines or nearby extrasynaptic shaft regions. Consistent with the inactivity-induced enrichment of synaptic GluN2A-containing NMDARs (i.e., synaptically evoked EPSCs; Fig. 6), we found that NMDAR-2P-EPSCs from dendritic spines of TTX-treated neurons exhibited faster decay kinetics than from morphologically similar control spines (CTL: $191.71 \pm 4.73 \mathrm{~ms}, n=18$; TTX: $145.07 \pm 16.44 \mathrm{~ms}, n=26 ; p<0.01$; Fig. $8 A-D)$. Strikingly, however, the decay kinetics of NMDAR-2P-EPSCs elicited from shaft regions of TTX-treated neurons were comparable to those elicited from shaft regions of control neurons (CTL: $209.72 \pm$ $10.80 \mathrm{~ms}, n=13$; TTX: $195.54 \pm 11.83 \mathrm{~ms}, n=19 ; p=0.32)$ and significantly longer than those from nearby spines (Fig. $8 A-C$ ). Whereas uncaging onto spines can in principle activate a mixture of synaptic and extrasynaptic receptors, uncaging onto shaft regions overwhelmingly activates extrasynaptic receptor populations. Thus, in stark contrast to the cell-wide homeostatic upregulation of surface GluA2-lacking AMPARs at both synaptic and extrasynaptic membrane regions, the TTX-induced enrichment of GluN2A-containing NMDARs occurs selectively at synapses. Collectively, by discriminating between synaptic and extrasynaptic glutamate receptor populations, our results expose intriguing differences in the regulatory mechanisms that dictate the synaptic targeting of AMPARs and NMDARs of defined subunit composition during homeostatic plasticity (Fig. 9A,B).

\section{Discussion}

Here, using a combination of biochemical, biophysical, and pharmacological approaches, we found that prolonged TTX treatment altered the subunit composition of both synaptic AMPARs and NMDARs in CA1 pyramidal neurons from organotypic hippocampal slices. Notably, we show that prolonged inactivity induced a robust upregulation of the AMPAR subunit GluA1 that resulted in a widespread, cell-wide, surface expression 
A
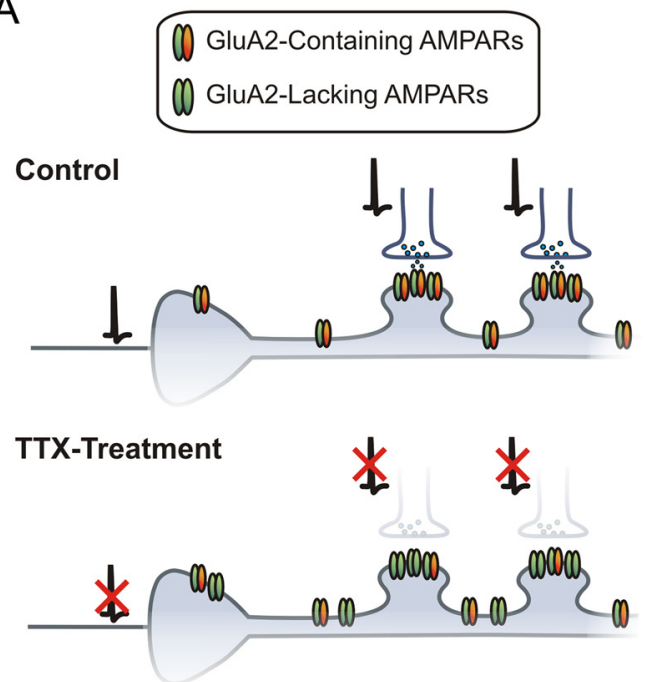

B
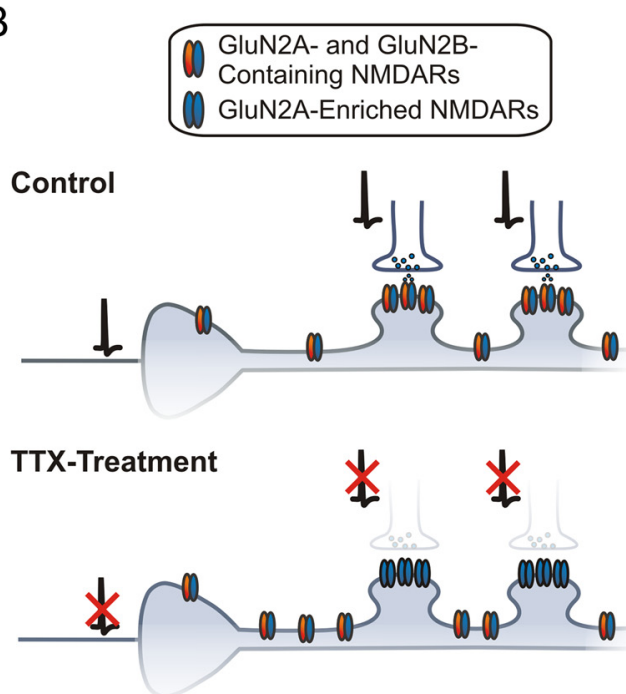

Figure 9. Differential subcellular targeting of glutamate receptor subtypes during HSP. A, Top, AMPARs containing the GluA2 subunit predominate at both synaptic and extrasynaptic regions of CA1 pyramidal neurons. Bottom, When network activity is silenced by prolonged TTX treatment, there is a homeostatic upregulation of GluA2-lacking AMPARs in both synaptic and extrasynaptic compartments of the neuronal membrane. B, Top, CA1 pyramidal neurons display a mixed population of NMDARs containing both GluN2A and GluN2B subunits. Bottom, When network activity is silenced by prolonged TTX treatment, there is an indiscriminate increase in surface NMDARs subunits; however, GluN2A-containing NMDARs are preferentially localized/stabilized at synapses.

of GluA2-lacking AMPARs. Remarkably, despite inducing a robust and generalized upregulation of the three major hippocampal NMDAR subunits, network silencing triggered a switch in the subunit composition of solely the synaptic population of NMDARs, leaving unaltered the composition of their extrasynaptic counterparts. Altogether, these findings highlight the notion that the homeostatic mechanisms used by neurons to adjust their excitability levels regulate synapse function in ways beyond solely modifying synaptic strength per se.

A number of previous studies have reported conflicting evidence regarding the subunit composition of AMPARs involved in homeostatic synaptic potentiation. A recent review (Lee, 2012a) attempted to reconcile these discrepancies by documenting differences in the pharmacological paradigms used to induce HSP. Specifically, it was highlighted that the selective regulation of GluA1 occurred after prolonged blockade of both network activity (i.e., TTX) and NMDARs (Ju et al., 2004; Sutton et al., 2006; Aoto et al., 2008), whereas both GluA1 and GluA2 expression were affected when neurons were treated with TTX alone (O'Brien et al., 1998; Gainey et al., 2009; Anggono et al., 2011). In contrast to this unifying picture, we provide here a number of complementary and converging lines of evidence indicating that TTX treatment alone led to a robust and selective upregulation of GluA1 expression and formation of GluA2-lacking AMPARs in CA1 pyramidal neurons in an organotypic slice preparation. The direct replacement of GluA2-containing AMPARs with higherconductance GluA2-lacking AMPARs during homeostatic plasticity offers an effective means to enhance synaptic strength without the need to increase receptor number or to increase spine volume. This scenario is consistent with homeostatic plasticity occurring at single synapses (Béïque et al., 2011) and is in line with manifestations of homeostatic synaptic plasticity in vivo (He et al., 2012).

It is pertinent to compare and contrast the mechanistic underpinnings of Hebbian and homeostatic synaptic strengthening, including those involving subunit composition of glutamate receptors. While a transient insertion of GluA2-lacking AMPARs has been observed following LTP induction (Plant et al., 2006; Guire et al., 2008), the role of this particular subtype of AMPARs in LTP is controversial (Adesnik and Nicoll, 2007; Gray et al., 2007). Likewise, the implication of GluA2-lacking AMPARs in homeostatic synaptic strengthening is also debated, as outlined above. These divergences may reflect the presence of distinct synaptic plasticity mechanisms that are heavily dependent on subtleties in experimental conditions and paradigms. Nevertheless, the homeostatic switch in NMDAR subunit composition we report here is highly analogous to that previously shown to occur during Hebbian LTP (Bellone and Nicoll, 2007). Indeed, LTP was shown to be accompanied by a GluN2B-containing toward GluN2Acontaining NMDAR subunit switch that exhibited a time course highly similar to that of the synaptic delivery of AMPARs. Although our results provide limited insights into the precise time course of the inactivity-induced subunit switches for both AMPARs and NMDARs, these homeostatic adaptive mechanisms might be occurring simultaneously. It is thus tempting to speculate that both Hebbian and homeostatic synaptic strengthening use common mechanisms involving the concerted upregulation of AMPARs and GluN2A-containing NMDARs. Future studies will be required to substantiate this possibility and further establish the extent of the molecular commonalities between Hebbian and homeostatic synaptic plasticity.

The homeostatic adjustments reported here for both AMPAR and NMDAR subunit composition likely influence Hebbian plasticity rules. Indeed, in vivo visual deprivation paradigms that lead to homeostatic upregulation of synapse function in visual cortex (Goel and Lee, 2007; Gao et al., 2010) impart a metaplastic influence that modifies the stimulus threshold for inducing LTP and LTD (Philpot et al., 2001, 2003), and spike-timing-dependent synaptic plasticity (Guo et al., 2012). These changes appear to be caused by an increased proportion of GluN2B-containing NMDARs at synapses, in an apparent contrast to what we report here. Whereas the various in vivo visual deprivation paradigms reduce thalamic synaptic input into visual cortex, it is unclear to what extent they reduce overall network excitability in the visual cortex. Thus, it is possible that the GluN2A enrichment we report here following prolonged TTX treatment represents a homeostatic response to prolonged neuronal silencing, whereas the GluN2B enrichment observed following visual deprivation re- 
flects a homeostatic response to a reduction in presynaptic activity. In support of this idea, selective presynaptic silencing of individual synapses has recently been shown to cause postsynaptic GluN2B enrichment (Lee et al., 2010). Conversely, the presence of calcium-permeable GluA2-lacking AMPARs following prolonged inactivity may also convey metaplastic influences to synapses, either by lowering the threshold for Hebbian synaptic potentiation, or even by imparting anti-Hebbian features (Lamsa et al., 2007). Future studies are required to better understand the influence of glutamate receptor composition on synaptic plasticity rules.

AMPARs and NMDARs of different subunit composition are differentially localized to synaptic and extrasynaptic membrane compartments. For instance, AMPARs containing GluA2/GluA3 subunits are found almost exclusively at synapses, whereas GluA1/GluA2-AMPARs occupy both synaptic and extrasynaptic membrane regions (Béique and Huganir, 2009; Lu et al., 2009). Moreover, GluN2A-containing NMDARs are believed to be preferentially stabilized at synapses over GluN2B-containing NMDARs (Groc et al., 2006). These subcellular distribution profiles are thought to arise through preferential interactions of specific AMPAR and NMDAR subunits, and/or auxiliary subunits, with PSD scaffolding proteins at synapses (Lau and Zukin, 2007; Shepherd and Huganir, 2007; Jackson and Nicoll, 2011). The differential subcellular distribution of AMPAR and NMDAR expression during HSP that we have described can be traced, at least in part, to the changes in subunit protein expression. Specifically, the selective upregulation of GluAl protein expression (over GluA2) was accompanied by a widespread enhancement of surface GluA2-lacking AMPARs, evident at both dendritic spines and extrasynaptic membrane regions. Such a cell-wide upregulation of AMPARs offers an effective means to account for the remarkable multiplicativity of homeostatic synaptic strengthening triggered by a somatic homeostatic sensing mechanism (Lee et al., 2013). Interestingly, the TTX-induced increase in NMDAR protein expression (both total and surface expression) was not subunit selective, as we detected an upregulation of GluN1, GluN2A, and GluN2B. Despite this generalized increase in NMDAR surface expression, synapses were specifically enriched with GluN2A-containing NMDARs during HSP, likely reflecting the preferential synaptic stabilization of this subunit compared with GluN2B-containing NMDARs. Thus, whereas the synaptic incorporation of GluA2-lacking AMPARs likely results from the bulk loading of these receptors onto the plasma membrane, the selective synaptic stabilization of GluN2A-containing NMDARs during HSP emphasizes the competitive interactions of GluN2A subunits for synaptic anchoring/scaffolding proteins.

The functional importance of extrasynaptic receptors is increasingly being recognized. For instance, extrasynaptic AMPARs and NMDARs can be recruited to and/or exchanged with synaptic receptor populations in a dynamic and highly regulated manner. Recent studies have shown that extrasynaptic AMPARs can shape synaptic transmission (Heine et al., 2008) and are required for LTP (Makino and Malinow, 2009; Granger et al., 2013). Moreover, extrasynaptic NMDARs can powerfully influence synaptic integration (Chalifoux and Carter, 2011; Lee, 2012b) and differentially regulate neuronal survival and death signaling pathways (Hardingham and Bading, 2003). The homeostatic regulation of the number and subunit composition of extrasynaptic glutamate receptors described here will, in principle, influence all of the functions ascribed to this population of receptors, thus broadening the functional implications of the homeostatic process.
Both in vitro and in vivo manifestations of homeostatic synaptic plasticity have been documented using several experimental paradigms. Homeostatic synapse regulation operates continuously "online" to enable tuning of cellular excitability in the face of perpetual alterations in neuronal firing activity. We have demonstrated that, in addition to triggering robust synaptic strengthening, the homeostatic process also involves changes in the subunit composition and subcellular distribution of both AMPARs and NMDARs. Thus, the homeostatic adjustment of synapse function is not limited to the regulation of synaptic strength, but likely impacts synaptic properties such as temporal integration of synaptic input and calciumdependent biochemical signaling. Future studies will be required to fully grasp the functional implications of these homeostatic regulations.

\section{References}

Adesnik H, Nicoll RA (2007) Conservation of glutamate receptor 2-containing AMPA receptors during long-term potentiation. J Neurosci 27:4598-4602. CrossRef Medline

Anggono V, Clem RL, Huganir RL (2011) PICK1 loss of function occludes homeostatic synaptic scaling. J Neurosci 31:2188-2196. CrossRef Medline

Aoto J, Nam CI, Poon MM, Ting P, Chen L (2008) Synaptic signaling by all-trans retinoic acid in homeostatic synaptic plasticity. Neuron 60:308320. CrossRef Medline

Arendt KL, Sarti F, Chen L (2013) Chronic inactivation of a neural circuit enhances LTP by inducing silent synapse formation. J Neurosci 33:20872096. CrossRef Medline

Bard L, Sainlos M, Bouchet D, Cousins S, Mikasova L, Breillat C, Stephenson FA, Imperiali B, Choquet D, Groc L (2010) Dynamic and specific interaction between synaptic NR2-NMDA receptor and PDZ proteins. Proc Natl Acad Sci U S A 107:19561-19566. CrossRef Medline

Béique JC, Huganir RL (2009) AMPA receptor subunits get their share of the pie. Neuron 62:165-168. CrossRef Medline

Béique JC, Lin DT, Kang MG, Aizawa H, Takamiya K, Huganir RL (2006) Synapse-specific regulation of AMPA receptor function by PSD-95. Proc Natl Acad Sci U S A 103:19535-19540. CrossRef Medline

Béique JC, Na Y, Kuhl D, Worley PF, Huganir RL (2011) Arc-dependent synapse-specific homeostatic plasticity. Proc Natl Acad Sci U S A 108: 816-821. CrossRef Medline

Bellone C, Nicoll RA (2007) Rapid bidirectional switching of synaptic NMDA receptors. Neuron 55:779-785. CrossRef Medline

Bowie D, Mayer ML (1995) Inward rectification of both AMPA and kainate subtype glutamate receptors generated by polyamine-mediated ion channel block. Neuron 15:453-462. CrossRef Medline

Chalifoux JR, Carter AG (2011) Glutamate spillover promotes the generation of NMDA spikes. J Neurosci 31:16435-16446. CrossRef Medline

Gainey MA, Hurvitz-Wolff JR, Lambo ME, Turrigiano GG (2009) Synaptic scaling requires the GluR2 subunit of the AMPA receptor. J Neurosci 29:6479-6489. CrossRef Medline

Gao M, Sossa K, Song L, Errington L, Cummings L, Hwang H, Kuhl D, Worley P, Lee HK (2010) A specific requirement of Arc/Arg3.1 for visual experience-induced homeostatic synaptic plasticity in mouse primary visual cortex. J Neurosci 30:7168-7178. CrossRef Medline

Goel A, Lee HK (2007) Persistence of experience-induced homeostatic synaptic plasticity through adulthood in superficial layers of mouse visual cortex. J Neurosci 27:6692-6700. CrossRef Medline

Granger AJ, Shi Y, Lu W, Cerpas M, Nicoll RA (2013) LTP requires a reserve pool of glutamate receptors independent of subunit type. Nature 493: 495-500. CrossRef Medline

Gray EE, Fink AE, Sariñana J, Vissel B, O'Dell TJ (2007) Long-term potentiation in the hippocampal CA1 region does not require insertion and activation of GluR2-lacking AMPA receptors. J Neurophysiol 98:24882492. CrossRef Medline

Groc L, Heine M, Cousins SL, Stephenson FA, Lounis B, Cognet L, Choquet D (2006) NMDA receptor surface mobility depends on NR2A-2B subunits. Proc Natl Acad Sci U S A 103:18769-18774. CrossRef Medline

Groth RD, Lindskog M, Thiagarajan TC, Li L, Tsien RW (2011) Beta Ca2+/ CaM-dependent kinase type II triggers upregulation of GluA1 to coordi- 
nate adaptation to synaptic inactivity in hippocampal neurons. Proc Natl Acad Sci U S A 108:828-833. CrossRef Medline

Guire ES, Oh MC, Soderling TR, Derkach VA (2008) Recruitment of calcium-permeable AMPA receptors during synaptic potentiation is regulated by CaM-kinase I. J Neurosci 28:6000-6009. CrossRef Medline

Guo Y, Huang S, de Pasquale R, McGehrin K, Lee HK, Zhao K, Kirkwood A (2012) Dark exposure extends the integration window for spike-timingdependent plasticity. J Neurosci 32:15027-15035. CrossRef Medline

Hardingham GE, Bading H (2003) The yin and yang of NMDA receptor signalling. Trends Neurosci 26:81-89. CrossRef Medline

Hartveit E, Veruki ML (2007) Studying properties of neurotransmitter receptors by non-stationary noise analysis of spontaneous postsynaptic currents and agonist-evoked responses in outside-out patches. Nat Protoc 2:434-448. CrossRef Medline

Harvey CD, Svoboda K (2007) Locally dynamic synaptic learning rules in pyramidal neuron dendrites. Nature 450:1195-1200. CrossRef Medline

He K, Petrus E, Gammon N, Lee HK (2012) Distinct sensory requirements for unimodal and cross-modal homeostatic synaptic plasticity. J Neurosci 32:8469-8474. CrossRef Medline

Heine M, Groc L, Frischknecht R, Béïque JC, Lounis B, Rumbaugh G, Huganir RL, Cognet L, Choquet D (2008) Surface mobility of postsynaptic AMPARs tunes synaptic transmission. Science 320:201-205. CrossRef Medline

Jackson AC, Nicoll RA (2011) The expanding social network of ionotropic glutamate receptors: TARPs and other transmembrane auxiliary subunits. Neuron 70:178-199. CrossRef Medline

Ju W, Morishita W, Tsui J, Gaietta G, Deerinck TJ, Adams SR, Garner CC, Tsien RY, Ellisman MH, Malenka RC (2004) Activity-dependent regulation of dendritic synthesis and trafficking of AMPA receptors. Nat Neurosci 7:244-253. CrossRef Medline

Kessels HW, Malinow R (2009) Synaptic AMPA receptor plasticity and behavior. Neuron 61:340-350. CrossRef Medline

Kim J, Tsien RW (2008) Synapse-specific adaptations to inactivity in hippocampal circuits achieve homeostatic gain control while dampening network reverberation. Neuron 58:925-937. CrossRef Medline

Kim J, Tsien RW, Alger BE (2012) An improved test for detecting multiplicative homeostatic synaptic scaling. PloS One 7:e37364. CrossRef Medline

Lamsa KP, Heeroma JH, Somogyi P, Rusakov DA, Kullmann DM (2007) Anti-Hebbian long-term potentiation in the hippocampal feedback inhibitory circuit. Science 315:1262-1266. CrossRef Medline

Lau CG, Zukin RS (2007) NMDA receptor trafficking in synaptic plasticity and neuropsychiatric disorders. Nat Rev Neurosci 8:413-426. CrossRef Medline

Lazar A, Pipa G, Triesch J (2009) SORN: a self-organizing recurrent neural network. Front Comput Neurosci 3:23. CrossRef Medline

Lee HK (2012a) Ca-permeable AMPA receptors in homeostatic synaptic plasticity. Front Mol Neurosci 5:17. CrossRef Medline

Lee KF (2012b) A unique mechanism of NMDA spike initiation supports a distinct role in synaptic input integration. J Neurosci 32:2913-2914. CrossRef Medline

Lee KF, Soares C, Beique JC (2013) Tuning into diversity of homeostatic synaptic plasticity. Neuropharmacology. Advance online publication. Retrieved July 18, 2013. doi:10.1016/j.neuropharm.2013.03.016. CrossRef Medline

Lee MC, Yasuda R, Ehlers MD (2010) Metaplasticity at single glutamatergic synapses. Neuron 66:859-870. CrossRef Medline

Lu W, Shi Y, Jackson AC, Bjorgan K, During MJ, Sprengel R, Seeburg PH, Nicoll RA (2009) Subunit composition of synaptic AMPA receptors revealed by a single-cell genetic approach. Neuron 62:254-268. CrossRef Medline
Makino H, Malinow R (2009) AMPA receptor incorporation into synapses during LTP: the role of lateral movement and exocytosis. Neuron 64:381390. CrossRef Medline

Matsuzaki M, Ellis-Davies GC, Nemoto T, Miyashita Y, Iino M, Kasai H (2001) Dendritic spine geometry is critical for AMPA receptor expression in hippocampal CA1 pyramidal neurons. Nat Neurosci 4:1086-1092. CrossRef Medline

Matsuzaki M, Honkura N, Ellis-Davies GC, Kasai H (2004) Structural basis of long-term potentiation in single dendritic spines. Nature 429:761-766. CrossRef Medline

O’Brien RJ, Kamboj S, Ehlers MD, Rosen KR, Fischbach GD, Huganir RL (1998) Activity-dependent modulation of synaptic AMPA receptor accumulation. Neuron 21:1067-1078. CrossRef Medline

Opazo P, Choquet D (2011) A three-step model for the synaptic recruitment of AMPA receptors. Mol Cell Neurosci 46:1-8. CrossRef Medline

Pérez-Otaño I, Ehlers MD (2005) Homeostatic plasticity and NMDA receptor trafficking. Trends Neurosci 28:229-238. CrossRef Medline

Philpot BD, Sekhar AK, Shouval HZ, Bear MF (2001) Visual experience and deprivation bidirectionally modify the composition and function of NMDA receptors in visual cortex. Neuron 29:157-169. CrossRef Medline

Philpot BD, Espinosa JS, Bear MF (2003) Evidence for altered NMDA receptor function as a basis for metaplasticity in visual cortex. J Neurosci 23:5583-5588. Medline

Plant K, Pelkey KA, Bortolotto ZA, Morita D, Terashima A, McBain CJ, Collingridge GL, Isaac JT (2006) Transient incorporation of native GluR2-lacking AMPA receptors during hippocampal long-term potentiation. Nat Neurosci 9:602-604. CrossRef Medline

Sah P, Hestrin S, Nicoll RA (1989) Tonic activation of NMDA receptors by ambient glutamate enhances excitability of neurons. Science 246 : 815-818. CrossRef Medline

Shepherd JD, Huganir RL (2007) The cell biology of synaptic plasticity: AMPA receptor trafficking. Annu Rev Cell Dev Biol 23:613-643. CrossRef Medline

Stoppini L, Buchs PA, Muller D (1991) A simple method for organotypic cultures of nervous tissue. J Neurosci Methods 37:173-182. CrossRef Medline

Sutton MA, Ito HT, Cressy P, Kempf C, Woo JC, Schuman EM (2006) Miniature neurotransmission stabilizes synaptic function via tonic suppression of local dendritic protein synthesis. Cell 125:785-799. CrossRef Medline

Thiagarajan TC, Lindskog M, Tsien RW (2005) Adaptation to synaptic inactivity in hippocampal neurons. Neuron 47:725-737. CrossRef Medline

Traynelis SF, Silver RA, Cull-Candy SG (1993) Estimated conductance of glutamate receptor channels activated during EPSCs at the cerebellar mossy fiber-granule cell synapse. Neuron 11:279-289. CrossRef Medline

Turrigiano GG (2008) The self-tuning neuron: synaptic scaling of excitatory synapses. Cell 135:422-435. CrossRef Medline

Turrigiano GG, Leslie KR, Desai NS, Rutherford LC, Nelson SB (1998) Activity-dependent scaling of quantal amplitude in neocortical neurons. Nature 391:892-896. CrossRef Medline

Tyler WJ, Pozzo-Miller L (2003) Miniature synaptic transmission and BDNF modulate dendritic spine growth and form in rat CA1 neurones. J Physiol 553:497-509. CrossRef Medline

Vicini S, Wang JF, Li JH, Zhu WJ, Wang YH, Luo JH, Wolfe BB, Grayson DR (1998) Functional and pharmacological differences between recombinant N-methyl-D-aspartate receptors. J Neurophysiol 79:555-566. Medline

Watt AJ, van Rossum MC, MacLeod KM, Nelson SB, Turrigiano GG (2000) Activity coregulates quantal AMPA and NMDA currents at neocortical synapses. Neuron 26:659-670. CrossRef Medline 